\title{
Capital Requirements, Market Power, and Risk-Taking in Banking
}

\author{
Rafael Repullo \\ CEMFI and CEPR
}

April 2002

\begin{abstract}
This paper presents a dynamic model of imperfect competition in banking where the banks can invest in a prudent or a gambling asset. We show that if intermediation margins are small, the banks' franchise values will be small, and in the absence of regulation only a gambling equilibrium will exist. In this case, capital requirements can ensure the existence of a prudent equilibrium, because they do not affect the banks' franchise values and reduce their gambling incentives by putting their equity at risk. In contrast, deposit interest rate ceilings may increase the banks' franchise values, but do not always guarantee the existence of a prudent equilibrium.
\end{abstract}

Keywords: bank regulation, capital requirements, deposit rate ceilings, market power, moral hazard, asset substitution, franchise values.

JEL Classification: G21, G28, D43.

I am very grateful to Javier Suarez for numerous conversations on bank regulation, and to Jesús Carro for his excellent research assistance. Address for correspondence: CEMFI, Casado del Alisal 5, 28014 Madrid, Spain. Email: repullo@cemfi.es. 


\section{Introduction}

It is well-known that an increase in bank competition that erodes the present value of the banks' future rents (their franchise or charter value) reduces their incentives to behave prudently. The standard regulatory response has been to tighten capital requirements: higher capital implies higher losses for the banks' shareholders in case of default, and hence lower incentives for risk-taking. However, in a recent paper, Hellmann, Murdock and Stiglitz (2000), henceforth HMS, observe that in addition to this capital at risk effect, there is a franchise value effect that goes in the opposite direction. In particular, they claim that higher capital requirements reduce the banks' franchise values, and hence the payoffs associated with prudent investment, so their overall effect is ambiguous.

The purpose of this paper is to reexamine the relationship between capital requirements, market power, and risk-taking in banking in the context of a dynamic model of imperfect competition in the deposit market where, following HMS, the banks can invest in either a prudent or a gambling asset. The gambling asset is dominated in terms of expected return by the prudent asset, but yields a higher payoff if the gamble succeeds. Imperfect competition is introduced by borrowing from the industrial organization literature on spatial competition, in particular Salop's (1979) circular road model with uniformly distributed consumers (depositors in our case). Banks are located symmetrically around the circle, and compete by offering deposit rates. Travelling to banks is costly for depositors, which is the source of the banks' market power. Like HMS, we assume that deposits are fully insured by a government agency. ${ }^{1}$

In the absence of capital requirements, the characterization of the equilibrium of this model is very simple. There are two possible types of (symmetric) equilibrium: a prudent equilibrium in which the banks invest in the prudent asset, and a gambling equilibrium in which the banks invest in the gambling asset. In both equilibria, the intermediation margin is equal to the ratio between the depositors' unit transport cost and the number of banks.

\footnotetext{
${ }^{1}$ This is mainly to simplify the analysis, because then the expected return of the deposits of any bank is just its deposit rate, regardless of the bank's investment decision. HMS go further, arguing that "the assumption of deposit insurance best reflects reality."
} 
We show that for low intermediation margins (i.e., very competitive markets) only the gambling equilibrium exists, for high margins (i.e., very monopolistic markets) only the gambling equilibrium exists, and for intermediate margins both types of equilibria exist. We also show that if the cost of capital exceeds the return of the prudent asset, capital requirements are always effective in ensuring the existence of a prudent equilibrium. The reason for this result is that an increase in capital requirements reduces equilibrium deposit rates in such a way that the banks' franchise value does not change. Hence only the capital at risk effect operates, so higher capital reduces the banks' incentives to invest in the gambling asset.

As an extension of this result we examine the case where capital requirements can discriminate in favor of investment in the prudent asset. We show that risk-based capital requirements are more efficient regulatory tools, because they can ensure the existence of a prudent equilibrium at a smaller cost in terms of bank capital.

Finally, we also analyze the effect of introducing deposit interest rate ceilings. Such regulation has been advocated by HMS as a way to boost the banks' franchise values and hence reduce their risk-taking incentives. We show that deposit rate ceilings ensure the existence of a prudent equilibrium for a larger set of parameter values. However, we also show that if either the success return of the gambling asset or the cost of bank capital are sufficiently high, deposit rate ceilings (both binding and nonbinding ${ }^{2}$ ) do not guarantee the existence of a prudent equilibrium.

As suggested by the title of the paper, our model has three main ingredients: (i) bank regulation (in the form of capital requirements, deposit rate ceilings, and deposit insurance), (ii) imperfect competition, and (iii) moral hazard in the choice of investment. Most of the literature has looked at combinations of either (i) and (ii), or (i) and (iii). The first class of papers includes Chiappori, Perez-Castrillo and Verdier (1995), who study the regulation of deposit rates in the context of a circular road model of banking competition in both the deposit and the loan market, and Matutes and Vives (1996), who discuss the effect of deposit insurance in a Hotelling model of competition in the deposit market. In the second class of papers, Furlong and Keeley (1989) show that higher capital requirements reduce risk-taking incentives in a state preference model of a bank that chooses the level of asset risk, Genotte

\footnotetext{
${ }^{2}$ Nonbinding ceilings have no effect on equilibrium deposit rates when the banks invest in the prudent asset, but may constrain the banks that deviate to the gambling investment.
} 
and Pyle (1991) note that this result may not obtain in a model where the bank endogenously decides the size of its portfolio, Rochet (1992) shows that the effect of capital requirements on risk-taking is ambiguous when the bank's investment decision is taken by a risk averse owner-manager, and Besanko and Kanatas (1996) show that if in addition to the moral hazard problem in the choice of investment there is a second moral hazard problem in the choice of monitoring effort, higher capital requirements may worsen the second problem and lead to higher risk.

The three ingredients have been considered in a static context by Keeley (1990), who introduces market power by assuming that banks can make positive net present value loans, showing that increased competition may lead to higher risk-taking. Matutes and Vives (2000) get a similar result in the context of a fully fledged model of imperfect competition in the deposit market, and support the use of deposit rate ceilings and direct asset restrictions as regulatory tools. In a dynamic context, there is the paper by Suarez (1994), who constructs a dynamic model of a single monopolistic bank that chooses in each period the volatility of its lognormally distributed asset portfolio. Using dynamic programming techniques he endogenizes the franchise value of the bank, and shows that the model has a bang-bang solution: when market power falls below a critical level, the solution jumps from minimal to maximal risk.

Our paper differs from Suarez (1994) in that we introduce a model of monopolistic competition in the deposit market, and we simplify the bank's asset choice by using the simple discrete setup of HMS. In addition, we assume that bank capital is costly, but otherwise the two models are very similar. On the other hand, our paper differs from HMS in the explicit modeling of competition in the deposit market, and in the way in which the cost of capital enters the value function of the banks: in our setup bank capital is inside capital provided by the existing shareholders, while they assume that it is outside capital raised in the stock market. A companion paper, Repullo (2002), discusses in detail the differences between the two approaches in a simpler model with exogenous deposit rates.

The remainder of this paper is organized as follows. Section 2 presents the model. Section 3 characterizes the equilibrium of the model when there is a minimum capital requirement. Section 4 analyzes the effects of introducing risk-based capital requirements and deposit interest rate ceilings, and Section 5 concludes. The proofs of all 
the results are contained in the Appendix.

\section{The Model}

Consider a discrete time, infinite horizon model of an economy with $n>2$ risk neutral banks. Each bank $j=1, \ldots, n$ receives from a regulator a license to operate at an initial date $t=0$. This license is withdrawn at any date when the bank is revealed to be insolvent, that is when the value of its assets is smaller than the value of its deposit liabilities. In this case a new bank is allowed to enter the market, so the total number of banks is always $n .^{3}$

The banks operate in a market with a continuum of measure 1 of overlapping generations of depositors distributed uniformly on a circumference of unit length. The $n$ banks are located symmetrically on this circumference. Depositors live for two dates, have a unit endowment in the first date of their life, and only want to consume in the second date of their life. So they will invest their initial endowment in the only asset that is available to them, namely bank deposits. We assume that travelling to banks around the circumference has a cost of $\mu$ times the distance between the depositor and the bank.

At each date $t$ the banks compete in this market by offering deposit rates. We will focus on symmetric equilibria in which all the banks choose the same deposit rate. Since depositors have a unit endowment and total measure 1 , in equilibrium each bank will get $1 / n$ deposits at each date. The banks can also raise equity capital, which has an infinitely elastic supply at an expected rate of return $\rho$. This can be rationalized by postulating that bank shareholders are infinitely lived agents with preferences linear in consumption with a discount rate $\rho$.

The funds raised by the banks can be invested in either of two assets: a prudent asset, yielding a net return $\alpha$, and a gambling asset, yielding a net return $\gamma$ with probability $1-\pi$, and -1 with probability $\pi$ (so the gross return when the gamble fails is zero). We assume that

$$
\gamma>\alpha \geq(1-\pi) \gamma-\pi
$$

\footnotetext{
${ }^{3}$ See Perotti and Suarez (2001) for an interesting model in which the number of banks goes down after a bank failure. They show the associated future increase in the rents of the surviving banks acts as an incentive to current prudent behavior.
} 
This means the gambling asset is dominated in terms of expected return by the prudent asset, but yields a higher return if the gamble succeeds. ${ }^{4}$ We also assume that

$$
\rho>\alpha
$$

so bank capital is costly in the sense that it requires an expected return higher than the return of the prudent asset.

The regulator requires the banks to hold a minimum capital $k$ per unit of deposits, and fully insures their deposits. For simplicity, we assume that deposit insurance premia are zero, and that deposit insurance payouts are financed by lump sum taxes on the old depositors.

The asset choice of any bank is not observed by the depositors or the regulator. However, the regulator can observe if the value of the bank's assets is smaller than the value of its deposit liabilities, in which case the bank is closed, ${ }^{5}$ its depositors are compensated, and a new bank enters the market.

\section{Characterization of Equilibrium}

To analyze the equilibrium of the model it is convenient to proceed in three stages. First, we consider the simple case where the banks can only invest in the prudent asset. Second, we discuss the case where the banks can only invest in the gambling asset. Finally, we look at the general case where the banks can invest in both assets. In all these cases we restrict attention to Markov strategies in which the past influences current play only through its effect on state variables. ${ }^{6}$

\subsection{The model with the prudent asset}

At each date $t$ each bank $j$ chooses the amount of capital $k_{j t}$ to hold per unit of deposits and the deposit rate $r_{j t}$ to offer, and invests all the funds raised in an asset that yields the safe return $\alpha$. To simplify the notation we will omit the subindex $t$

\footnotetext{
${ }^{4}$ HMS assume that $\alpha>(1-\pi) \gamma-\pi$, but the strict inequality is not needed, so the return of the gambling asset could be a mean preserving spread of the return of the prudent asset.

${ }^{5}$ See Repullo (2000) for a model in which the regulator's incentives for closing the bank are explicitly analyzed.

${ }^{6}$ See Fudenberg and Tirole (1991), Chapter 13.
} 
and simply write the bank's decision variables as $k_{j}$ and $r_{j}$. Given the existence of a capital requirement, the bank's choice of capital must satisfy the constraint $k_{j} \geq k$.

To obtain the symmetric Nash equilibrium of the model of bank competition we first compute the demand for deposits of bank $j$ when it offers the deposit rate $r_{j}$ while the remaining $n-1$ banks offer the rate $r$. In this situation bank $j$ only has two effective competitors, namely banks $j-1$ and $j+1$. A depositor located at distance $z$ from bank $j$ and distance $1 / n-z$ from bank $j+1$ will be indifferent between going to $j$ or to $j+1$ if the return net of transport costs is the same, that is if

$$
r_{j}-\mu z=r-\mu(1 / n-z)
$$

Solving for $z$ in this equation yields

$$
z\left(r_{j}, r\right)=\frac{1}{2 n}+\frac{r_{j}-r}{2 \mu}
$$

so taking into account the symmetric market area between bank $j$ and bank $j-1$ gives the following demand for deposits of bank $j$ :

$$
D\left(r_{j}, r\right)=2 z\left(r_{j}, r\right)=\frac{1}{n}+\frac{r_{j}-r}{\mu} .
$$

Notice that for $r_{j}=r$ we have $z\left(r_{j}, r\right)=1 / 2 n$, i.e. the mid point between the two banks, and $D\left(r_{j}, r\right)=1 / n$.

The problem of the bank's shareholders at date $t$ is

$$
\max _{k_{j} \geq k, r_{j}}\left[-k_{j} D\left(r_{j}, r\right)+\frac{1}{1+\rho}\left(\alpha-r_{j}+(1+\alpha) k_{j}\right) D\left(r_{j}, r\right)+\frac{1}{1+\rho} V_{P}\right] .
$$

The first term in this expression is, with negative sign, the equity contribution of the bank's shareholders at date $t$ (recall that $k_{j}$ is the amount of capital per unit of deposits). The second term is the discounted value of the bank equity capital at date $t+1$, which equals the value of its assets, $(1+\alpha)\left(1+k_{j}\right) D\left(r_{j}, r\right)$, minus the value of its deposit liabilities, $\left(1+r_{j}\right) D\left(r_{j}, r\right)$. Notice that

$$
(1+\alpha)\left(1+k_{j}\right)-\left(1+r_{j}\right)=\alpha-r_{j}+(1+\alpha) k_{j}
$$

which is the expression that appears in the objective function. In other words, the shareholders get (per unit of deposits) the intermediation margin $\alpha-r_{j}$ plus the gross 
return $1+\alpha$ on investing their capital $k_{j}$ in the prudent asset. The third term in (4) is the discounted value of remaining open at date $t+1$ and hence obtaining a stream of profits at future dates $t+2, t+3$, etc. The discount rate used in the last two terms is the cost of capital $\rho$.

Differentiating the objective function (4) with respect to $k_{j}$, and using assumption (2), gives

$$
\left(-1+\frac{1+\alpha}{1+\rho}\right) D\left(r_{j}, r\right)=\frac{\alpha-\rho}{1+\rho} D\left(r_{j}, r\right)<0
$$

so we have a corner solution $k_{j}=k$. Obviously, since the cost of capital $\rho$ is greater than the return $\alpha$ of the prudent asset, it makes no sense for the bank shareholders to hold excess capital.

Substituting this result into the objective function (4), differentiating it with respect to $r_{j}$, and using the demand function (3), gives the following first order condition:

$$
-\frac{k}{\mu}+\frac{1}{1+\rho}\left[\frac{\alpha-r_{j}+(1+\alpha) k}{\mu}-\left(\frac{1}{n}+\frac{r_{j}-r}{\mu}\right)\right]=0 .
$$

The (unique) symmetric Nash equilibrium is then obtained by setting $r_{j}=r$ in this condition and solving for $r$, which gives the equilibrium deposit rate when the banks can only invest in the prudent asset:

$$
r_{P}(k)=\alpha-\frac{\mu}{n}-(\rho-\alpha) k
$$

Since $\rho-\alpha>0$ by assumption (2), the equilibrium deposit rate is decreasing in the capital requirement $k .^{7}$

The equilibrium intermediation margin, defined as the difference between the asset return $\alpha$ and the equilibrium deposit rate $r_{P}(k)$, is

$$
\alpha-r_{P}(k)=\frac{\mu}{n}+(\rho-\alpha) k
$$

Hence the margin is increasing in the ratio between the unit transport cost $\mu$ and the number of banks $n$, in the differential between the cost of capital $\rho$ and the return of the prudent asset $\alpha$, and in the level of the capital requirement $k$. For $k=0$ the margin equals the ratio $\mu / n$, and for $k \geq 0$ the margin is such that

$$
-k+\frac{1}{1+\rho}\left(\alpha-r_{P}(k)+(1+\alpha) k\right)=-k+\frac{1}{1+\rho}\left(\frac{\mu}{n}+(1+\rho) k\right)=\frac{1}{1+\rho} \frac{\mu}{n} .
$$

\footnotetext{
${ }^{7}$ We are not taking explicitly into account non-negativity constraints on interest rates, simply assuming that parameter values are such that $r_{P}(k) \geq 0$.
} 
This means that the outcome of the competition for deposits is such that the banks' shareholders get (per unit of deposits) the margin $\mu / n$ plus the required rate of return on their capital. Hence, as in Salop's (1979) model, the ratio $\mu / n$ is the appropriate measure of the banks' market power.

Substituting $k_{j}=k$ and $r_{j}=r=r_{P}(k)$ into the objective function (4), and taking into account the fact that by dynamic programming the maximized value is also $V_{P}$, yields the equation

$$
V_{P}=\frac{1}{1+\rho}\left(\frac{\mu}{n^{2}}+V_{P}\right)
$$

so the banks' franchise value is

$$
V_{P}=\frac{\mu}{\rho n^{2}}
$$

This expression is easy to understand: Each bank raises $1 / n$ deposits at each date $t=0,1,2, \ldots$, and gets profits (net of the cost of capital) equal to $\mu / n^{2}$ at each date $t=1,2,3, \ldots$, with present value at $t=0$ equal to

$$
\left[\frac{1}{1+\rho}+\frac{1}{(1+\rho)^{2}}+\frac{1}{(1+\rho)^{3}}+\ldots\right] \frac{\mu}{n^{2}}=\frac{\mu}{\rho n^{2}} .
$$

The franchise value $V_{P}$ is increasing in the transport cost $\mu$ and decreasing in the number of banks $n$ and in the cost of capital $\rho$. Interestingly, $V_{P}$ does not depend on the return $\alpha$ of the prudent asset, since this return (net of the intermediation margin) is entirely paid to the depositors. Also, $V_{P}$ does not depend on the capital requirement $k$, because the negative effect of the capital requirement is exactly compensated by a reduction in the equilibrium deposit rate $r_{P}(k)$. Hence the cost of the capital requirement is entirely pass onto the depositors, which are correspondingly made worse off.

\subsection{The model with the gambling asset}

Suppose next that at each date $t$ each bank $j$ chooses the amount of capital $k_{j} \geq k$ to hold per unit of deposits and the deposit rate $r_{j}$ to offer, and invests all the funds raised in an asset that yields a high return $\gamma$ with probability $1-\pi$, and a low return -1 with probability $\pi$.

When the gamble fails, the value of the bank's assets is zero and the bank is closed 
by the regulator, so by limited liability its shareholders get zero. ${ }^{8}$ Hence the problem of the bank's shareholders at date $t$ is

$$
\max _{k_{j} \geq k, r_{j}}\left[-k_{j} D\left(r_{j}, r\right)+\frac{1-\pi}{1+\rho}\left(\gamma-r_{j}+(1+\gamma) k_{j}\right) D\left(r_{j}, r\right)+\frac{1-\pi}{1+\rho} V_{G}\right],
$$

where $V_{G}$ is the bank's franchise value in the model with the gambling asset. Thus, the bank's objective function is similar to that of the model with a prudent asset, except that now the asset return is $\gamma$ instead of $\alpha$, and the second and third terms are multiplied by the probability $1-\pi$ that the gamble succeeds.

Differentiating the objective function (7) with respect to $k_{j}$, and using assumptions (1) and (2), gives

$$
\left(-1+\frac{(1-\pi)(1+\gamma)}{1+\rho}\right) D\left(r_{j}, r\right) \leq\left(-1+\frac{(1+\alpha)}{1+\rho}\right) D\left(r_{j}, r\right)=\frac{\alpha-\rho}{1+\rho} D\left(r_{j}, r\right)<0
$$

so we also have a corner solution $k_{j}=k$.

Substituting this result into the objective function (7), differentiating it with respect to $r_{j}$, and using the demand function (3), gives the following first order condition:

$$
-\frac{k}{\mu}+\frac{1-\pi}{1+\rho}\left[\frac{\gamma-r_{j}+(1+\gamma) k}{\mu}-\left(\frac{1}{n}+\frac{r_{j}-r}{\mu}\right)\right]=0 .
$$

The (unique) symmetric Nash equilibrium is then obtained by setting $r_{j}=r$ in this condition and solving for $r$, which gives the equilibrium deposit rate when the banks can only invest in the gambling asset:

$$
r_{G}(k)=\gamma-\frac{\mu}{n}-\frac{\rho-[(1-\pi) \gamma-\pi]}{1-\pi} k .
$$

Since by assumptions (2) and (1) we have

$$
\frac{\rho-[(1-\pi) \gamma-\pi]}{1-\pi}>\frac{\alpha-[(1-\pi) \gamma-\pi]}{1-\pi} \geq 0
$$

the coefficient of $k$ in (8) is negative, so the equilibrium deposit rate is decreasing in the capital requirement $k$.

\footnotetext{
${ }^{8}$ Notice that if the return when the gamble fails were greater than -1 (as in HMS), then a sufficiently large capital buffer would prevent closure. Our analysis could be easily extended to this case, at the cost of complicating the notation and the discussion of the results.
} 
The equilibrium intermediation margin, defined as the difference between the success return $\gamma$ and the equilibrium deposit rate $r_{G}(k)$, is

$$
\gamma-r_{G}(k)=\frac{\mu}{n}+\frac{\rho-[(1-\pi) \gamma-\pi]}{1-\pi} k .
$$

Hence the margin is increasing in the ratio between the unit transport cost $\mu$ and the number of banks $n$, in the differential between the cost of capital $\rho$ and the expected return of the gambling asset $(1-\pi) \gamma-\pi$, in the probability of failure $\pi$, and in the level of the capital requirement $k$. For $k=0$ the margin equals the ratio $\mu / n$, and for $k \geq 0$ the margin is such that

$$
-k+\frac{1-\pi}{1+\rho}\left(\gamma-r_{G}(k)+(1+\gamma) k\right)=-k+\frac{1-\pi}{1+\rho}\left(\frac{\mu}{n}+\frac{1+\rho}{1-\pi} k\right)=\frac{1-\pi}{1+\rho} \frac{\mu}{n} .
$$

Hence, as in the model with the prudent asset, the outcome of the competition for deposits is such that the banks' shareholders get (per unit of deposits) the margin $\mu / n$ plus the required rate of return on their capital.

Substituting $k_{j}=k$ and $r_{j}=r=r_{G}(k)$ into the objective function (7), and taking into account the fact that by dynamic programming the maximized value is also $V_{G}$, yields the equation

$$
V_{G}=\frac{1-\pi}{1+\rho}\left(\frac{\mu}{n^{2}}+V_{G}\right)
$$

so the bank's franchise value is

$$
V_{G}=\frac{(1-\pi) \mu}{(\rho+\pi) n^{2}}
$$

As before, this expression is easy to understand: each bank raises $1 / n$ deposits at each date $t=0,1,2, \ldots$, and gets profits (net of the cost of capital) equal to $\mu / n^{2}$ at each date $t=1,2,3, \ldots$ with probability $(1-\pi)^{t}$, a stream that has present value at $t=0$ equal to

$$
\left[\frac{1-\pi}{1+\rho}+\left(\frac{1-\pi}{1+\rho}\right)^{2}+\left(\frac{1-\pi}{1+\rho}\right)^{3}+\ldots\right] \frac{\mu}{n^{2}}=\frac{(1-\pi) \mu}{(\rho+\pi) n^{2}}
$$

Hence the one-period net expected return, $(1-\pi) \mu / n^{2}$, is discounted at a rate that is the sum of the opportunity cost $\rho$ of bank capital and the probability $\pi$ that the gamble fails and the bank is closed by the regulator. ${ }^{9}$

\footnotetext{
${ }^{9}$ Notice the similarity with the discount rate in models where consumers face in each period a constant probability of death; see Blanchard (1985).
} 
The franchise value $V_{G}$ is increasing in the transport cost $\mu$ and decreasing in the number of banks $n$, the cost of capital $\rho$, and the probability of failure $\pi$. As in the case of the model with the prudent asset, the franchise value $V_{G}$ does not depend on the success return $\gamma$ of the prudent asset, since this return (net of the intermediation margin) is entirely paid to the depositors. Also, $V_{G}$ does not depend on the capital requirement $k$, because the negative effect of the capital requirement is exactly compensated by a reduction in the equilibrium deposit rate $r_{G}(k)$.

\subsection{The general model}

If the banks can invest in either the prudent or the gambling asset, there are two possible types of symmetric equilibria: one in which all the banks invest in the prudent asset, and another one in which all the banks invest in the gambling asset. By the arguments in the previous subsections, it is clear that in no case the banks will want to hold any excess capital, so we can set $k_{j}=k$ and focus on the choice of deposit rates and type of investment.

A prudent equilibrium will exist if no bank $j$ has an incentive to deviate from a situation in which all the banks offer the deposit rate $r_{P}(k)$ and invest in the prudent asset, that is if the following no gambling condition holds:

$$
\max _{r_{j}}\left[-k D\left(r_{j}, r_{P}(k)\right)+\frac{1-\pi}{1+\rho}\left(\gamma-r_{j}+(1+\gamma) k\right) D\left(r_{j}, r_{P}(k)\right)+\frac{1-\pi}{1+\rho} V_{P}\right] \leq V_{P}
$$

The left hand side of this expression is the present value of the deviation to the gambling strategy at any date $t$, while the right hand side is the value of the bank in the prudent equilibrium.

A gambling equilibrium will exist if no bank $j$ has an incentive to deviate from a situation in which all the banks offer the deposit rate $r_{G}(k)$ and invest in the gambling asset, that is if the following no prudent condition holds:

$$
\max _{r_{j}}\left[-k D\left(r_{j}, r_{G}(k)\right)+\frac{1}{1+\rho}\left(\alpha-r_{j}+(1+\alpha) k\right) D\left(r_{j}, r_{G}(k)\right)+\frac{1}{1+\rho} V_{G}\right] \leq V_{G} .
$$

The left hand side of this expression is the present value of the deviation to the prudent strategy at any date $t$, while the right hand side is the value of the bank in the gambling equilibrium. 
We can now state the main result of this section.

Proposition 1 There are two critical values

$$
m_{P}(k)=\frac{\gamma-\alpha-\delta k}{2(h-1)} \quad \text { and } \quad m_{G}(k)=\frac{h(\gamma-\alpha-\delta k)}{2(h-1)}=h m_{P}(k),
$$

with

$$
h=\sqrt{\frac{\rho+\pi}{(1-\pi) \rho}}>1
$$

and

$$
\delta=\alpha-\gamma+\frac{\pi(1+\rho)}{1-\pi}>0
$$

such that a prudent equilibrium exists if $\mu / n \geq m_{P}(k)$, and a gambling equilibrium exists if $\mu / n \leq m_{G}(k)$.

The critical values $m_{P}(k)$ and $m_{G}(k)$ defined in (12) are linearly decreasing functions of the capital requirement $k$. Moreover, since $h>1$ their intercepts $m_{P}$ and $m_{G}$ satisfy

$$
m_{P}=m_{P}(0)<m_{G}(0)=m_{G},
$$

and we also have

$$
m_{P}(\widehat{k})=m_{G}(\widehat{k})=0,
$$

for

$$
\widehat{k}=\frac{\gamma-\alpha}{\delta}
$$

Since $\gamma>\alpha$ by assumption (1) and $\delta>0$ by Proposition 1, we have $\widehat{k}>0$. Hence we have the situation depicted in Figure 1. In region $\mathrm{P}$ the intermediation margin $\mu / n$ is above the line $m_{G}(k)$ and only the prudent equilibrium exists. In region $\mathrm{G}$ the margin $\mu / n$ is below the line $m_{P}(k)$ and only the gambling equilibrium exists. And in region $\mathrm{P}+\mathrm{G}$ where the margin $\mu / n$ is between the two lines both types of equilibria exist.

Comparing the equilibrium deposit rates $r_{P}(k)$ and $r_{G}(k)$ given by (5) and (8), respectively, we get

$$
r_{G}(k)-r_{P}(k)=\gamma-\alpha-\delta k \text {. }
$$




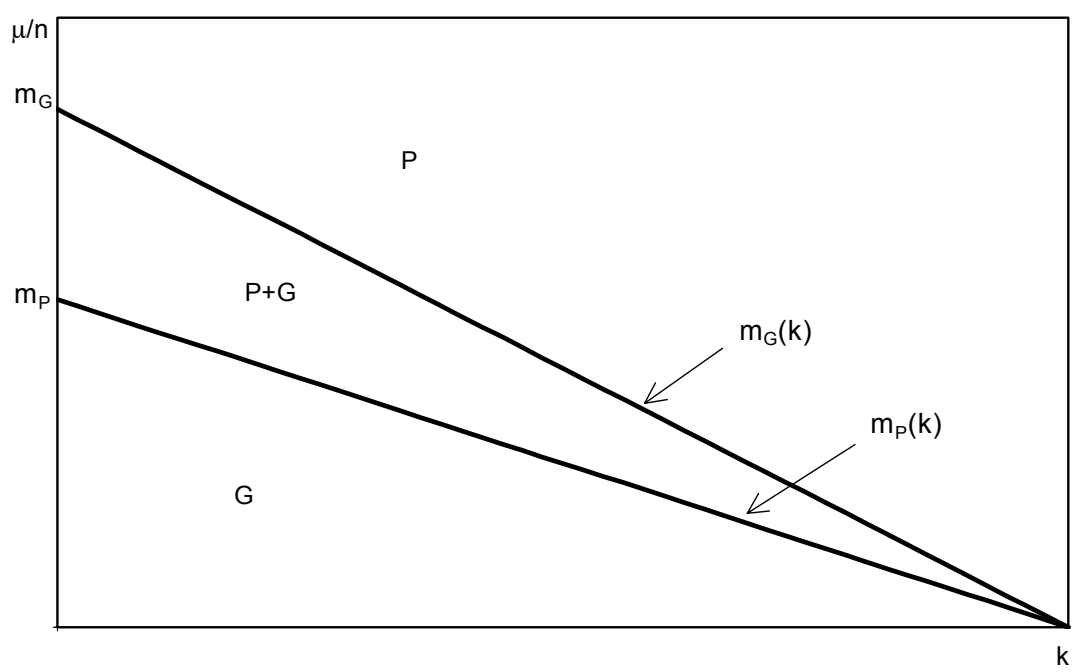

Figure 1: Characterization of equilibrium with capital requirements

Hence by the definition (15) of $\widehat{k}$ we conclude that in region $\mathrm{P}+\mathrm{G}$ where both types of equilibria exist we have $r_{G}(k)>r_{P}(k)$, so the gambling equilibrium is characterized by higher deposit rates. ${ }^{10}$

Also, comparing the bank's franchise values $V_{P}$ and $V_{G}$ given by (6) and (9), respectively, we get

$$
V_{G}-V_{P}=\frac{(1-\pi) \mu}{(\rho+\pi) n^{2}}-\frac{\mu}{\rho n^{2}}=-\frac{\pi(1+\rho)}{\rho(\rho+\pi)} \frac{\mu}{n^{2}}<0,
$$

so in region $\mathrm{P}+\mathrm{G}$ where both types of equilibria exist the banks are worse off in the gambling equilibrium.

Therefore high values of the measure $\mu / n$ of the banks' market power are conducive to the prudent equilibrium. The intuition for this result is fairly obvious. If the banks obtain large rents when open they have an incentive to choose the prudent strategy in order to preserve these rents. However, for intermediate values of the margin $\mu / n$, the strategic interaction among the banks generates multiple equilibria: if all the banks set the high deposit rate $r_{G}(k)$ and choose the gambling strategy, then a deviating bank choosing the prudent strategy will have to offer lower deposit rates, it will get

\footnotetext{
${ }^{10}$ However this does not mean that the depositors are necessarily better off in the gambling equilibrium, since the banks fail with positive probability, in which case the depositors are taxed to finance the deposit insurance payouts.
} 
fewer deposits, and as a result the deviation may not be profitable.

The effect of the parameters of the model on the characterization of the regions in the $k-\mu / n$ space is easy to derive by simply looking at the effect of changes in these parameters on the critical values $m_{P}, m_{G}$ and $\widehat{k}$ that determine the intersections of the linear functions $m_{P}(k)$ and $m_{G}(k)$ with the two axis.

In particular, it is immediate to check that $m_{P}, m_{G}$ and $\widehat{k}$ are all increasing in the spread $\gamma-\alpha$ between the success return of the gambling asset and the return of the prudent asset. Hence when the gambling asset becomes relatively more attractive, a gambling equilibrium is more likely to obtain.

On the other hand, $m_{P}, m_{G}$ and $\widehat{k}$ are all decreasing in the probability $\pi$ of failure of the gambling asset, ${ }^{11}$ so an increase in the probability $1-\pi$ of obtaining the future rents associated with the gambling strategy has the same qualitative effect as an increase in the spread $\gamma-\alpha$.

Finally, the effect of the cost of capital $\rho$ is more complicated since it increases the critical values $m_{P}$ and $m_{G}$, and it reduces the critical value $\widehat{k}^{12}$ The effect on the intercepts comes from the fact that an increase in $\rho$ reduces the present value of the higher future rents associated with the prudent strategy, making it relatively less attractive than the gambling strategy. But at the same time, the capital requirement has more bite for the gambling strategy, so for large values of $k$ a prudent equilibrium is more likely to obtain. Hence an increase in the cost of capital has a negative effect on the banks' incentives for prudent investment behavior, unless they operate in an environment with high capital requirements.

The implications of our results for capital regulation are immediate. If an increase in bank competition (which reduces the intermediation margin $\mu / n$ ) pushes the banks to the gambling equilibrium region, then an increase in the capital requirement $k$ can always shift them back to the region where a prudent equilibrium exists. In particular, assuming that whenever we have multiple equilibria the banks will play the Pareto dominating prudent equilibrium, the minimum capital requirement $k^{*}$ required to avoid gambling is defined by the condition $m_{P}\left(k^{*}\right)=\mu / n$, which by (12) gives

$$
k^{*}=\frac{1}{\delta}\left(\gamma-\alpha-2(h-1) \frac{\mu}{n}\right) .
$$

\footnotetext{
${ }^{11}$ Since $m_{P}$ and $m_{G}$ are decreasing in $h$ and $\partial h / \partial \pi>0$, and $\widehat{k}$ is decreasing in $\delta$ and $\partial \delta / \partial \pi>0$.
}

${ }^{12}$ Since $m_{P}$ and $m_{G}$ are decreasing in $h$ and $\partial h / \partial \rho<0$, and $\widehat{k}$ is decreasing in $\delta$ and $\partial \delta / \partial \rho>0$. 
By our previous discussion it is clear that

$$
\frac{\partial k^{*}}{\partial(\mu / n)}<0, \quad \frac{\partial k^{*}}{\partial(\gamma-\alpha)}>0, \quad \text { and } \quad \frac{\partial k^{*}}{\partial \pi}<0
$$

so the minimum requirement $k^{*}$ is decreasing in the intermediation margin $\mu / n$ and in the probability $\pi$ of failure of the gambling asset, and is increasing in the spread $\gamma-\alpha$ between the success return of the gambling asset and the return of the prudent asset. On the other hand, the effect of the cost of capital $\rho$ on the minimum requirement $k^{*}$ is ambiguous.

Hence we conclude that capital requirements are good for fostering prudent bank behavior, although they have a negative impact on depositors who bear the burden of the requirement in the form of lower deposit rates. In addition, the minimum required capital should be higher in environments with relatively attractive gambling assets (in terms of either upside returns or success probabilities), and/or with low intermediation margins.

\section{Extensions}

In the previous section we have shown that flat-rate capital requirements are an effective policy instrument for addressing the banks' incentives for risk-taking. We now examine two alternative ways of inducing the banks to choose prudent investment strategies. The first one is to have risk-based capital requirements, that is capital requirements that discriminate in favor of investment in the prudent asset. The second one is to introduce deposit interest rate ceilings, that is an upper bound on the rates that banks are allowed to pay to depositors.

\subsection{Risk-based capital requirements}

Suppose that the banks are subject to a capital requirement $k_{P}$ if they invest in the prudent asset and $k_{G}$ if they invest in the gambling asset, with $k_{P}<k_{G}$. Moreover, to simplify the presentation, assume that $k_{P}=0$ and $k_{G}=k>0$, and let

$$
r_{P}=r_{P}(0)=\alpha-\frac{\mu}{n}
$$

denote the deposit rate in the prudent equilibrium. 
A prudent equilibrium will exist if no bank $j$ has an incentive to deviate from a situation in which all the banks offer the deposit rate $r_{P}$ and invest in the prudent asset, that is if the following no gambling condition holds:

$$
\max _{r_{j}}\left[-k D\left(r_{j}, r_{P}\right)+\frac{1-\pi}{1+\rho}\left(\gamma-r_{j}+k(1+\gamma)\right) D\left(r_{j}, r_{P}\right)+\frac{1-\pi}{1+\rho} V_{P}\right] \leq V_{P} .
$$

The left hand side of this expression is the present value of the deviation to the gambling strategy at any date $t$, which involves a capital charge $k$ per unit of deposits, while the right hand side is the value of the bank in the prudent equilibrium.

A gambling equilibrium will exist if no bank $j$ has an incentive to deviate from a situation in which all the banks offer the deposit rate $r_{G}(k)$ and invest in the gambling asset, that is if the following no prudent condition holds:

$$
\max _{r_{j}}\left[\frac{1}{1+\rho}\left(\alpha-r_{j}\right) D\left(r_{j}, r_{G}(k)\right)+\frac{1}{1+\rho} V_{G}\right] \leq V_{G} .
$$

The left hand side of this expression is the present value of the deviation to the prudent strategy at any date $t$, which involves a zero capital charge, while the right hand side is the value of the bank in the gambling equilibrium.

We can now prove the following result.

Proposition 2 If the regulator imposes a capital requirement $k$ for investment in the gambling asset and no requirement for investment in the prudent asset, there are two critical values

$$
m_{P}^{\prime}(k)=\frac{\gamma-\alpha-\delta^{\prime} k}{2(h-1)} \quad \text { and } \quad m_{G}^{\prime}(k)=\frac{h\left(\gamma-\alpha-\delta^{\prime} k\right)}{2(h-1)}=h m_{P}^{\prime}(k),
$$

where $h$ is given by (13) and

$$
\delta^{\prime}=\frac{1+\rho}{1-\pi}-(1+\gamma)>0,
$$

such that a prudent equilibrium exists if $\mu / n \geq m_{P}^{\prime}(k)$, and a gambling equilibrium exists if $\mu / n \leq m_{G}^{\prime}(k)$.

Comparing the definitions of $\delta$ and $\delta^{\prime}$ in (14) and (20), it is immediate to check that

$$
\delta=\alpha-\gamma+\frac{\pi(1+\rho)}{1-\pi}<\frac{1+\rho}{1-\pi}-(1+\gamma)=\delta^{\prime}
$$


if and only if $\alpha<\rho$, which holds by assumption (2). Hence the functions $m_{P}^{\prime}(k)$ and $m_{G}^{\prime}(k)$ in (19) that characterize the equilibria with risk-based capital requirements are steeper than the functions $m_{P}(k)$ and $m_{G}(k)$ in (12) that characterize the equilibria under flat-rate capital requirements, so the former will intersect the horizontal axis at a point $\widehat{k}^{\prime}<\widehat{k}$. This implies that the region above the line $m_{G}^{\prime}(k)$ where only a prudent equilibrium exists becomes larger, and the regions below the line $m_{P}^{\prime}(k)$ and between the two lines where, respectively, only a gambling equilibrium and both types of equilibria exist become smaller. This is illustrated in Figure 2.

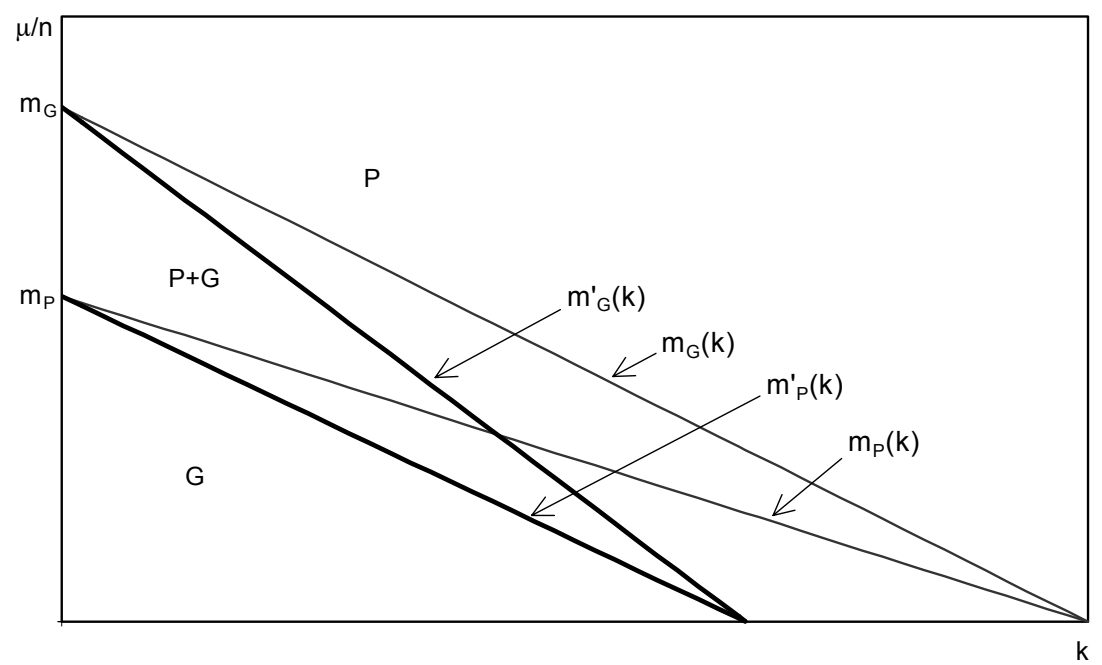

Figure 2: Characterization of equilibrium with risk-based capital requirements

The conclusion is then that risk-based capital requirements are more efficient tools for the regulator, because they can ensure the existence of a prudent equilibrium at a smaller cost in terms of bank capital. However, we have started our analysis with the assumption that the asset choices of the banks are not observed by the regulator, for otherwise he could directly prevent the banks from investing in the gambling asset. So how could the regulator enforce a risk-based capital requirement if he does not observe the characteristics of the banks' portfolios?

A possible answer to this question would be to set up a regulatory structure that makes it incentive compatible for the banks to reveal their asset choices to the regulator, for example by offering them the possibility to use their own risk 
management systems in order to compute the capital that they are required to hold. In fact, one can interpret the proposed reform of the Basel Capital Accord as a way to induce the banks to reveal private information about their loan portfolios by effectively reducing their capital requirement. ${ }^{13}$

\subsection{Deposit rate ceilings}

We now examine the effects a regulation that prevents banks from offering deposit rates above a ceiling $\bar{r}$. Such a regulation has been advocated by HMS as an efficient way to control risk-shifting incentives. We will show deposit rate ceilings expand the prudent equilibrium region, but that there is a large set of parameter values for which no ceiling can ensure the existence of a prudent equilibrium.

In what follows we assume that there are no capital requirements $(k=0)$ and that the intermediation margin is sufficiently low $\left(\mu / n<m_{P}\right)$, so in the absence of a deposit rate ceiling only the gambling equilibrium would exist. We also explicitly assume that $\alpha>\mu / n$, so $r_{P}=\alpha-\mu / n>0$.

Following HMS we consider two types of deposit rate ceilings. Nonbinding ceilings are such that $\bar{r} \geq r_{P}$, so if there is a prudent equilibrium (that is, if the deviation to the gambling strategy is no longer profitable) the deposit rate will be $r_{P}$. Binding ceilings are such that $\bar{r}<r_{P}$, so in a prudent equilibrium the deposit rate will be $\bar{r}$. The former are especially attractive, since they can achieve their aim without distorting the level of deposit rates.

If the regulator introduces a ceiling $\bar{r}$, and as a result a prudent equilibrium exists, the banks' franchise value will be

$$
V_{P}(\bar{r})=\max \left\{\frac{\alpha-\bar{r}}{\rho n}, \frac{\mu}{\rho n^{2}}\right\} .
$$

To explain this expression notice that if the ceiling is not binding we have the same franchise value as in (6), namely $\mu / \rho n^{2}$. On the other hand if the ceiling is binding, the banks will get profits $(\alpha-\bar{r}) / n$ at each date, so the present value of this flow will be $(\alpha-\bar{r}) / \rho n$. Since $(\alpha-\bar{r}) / \rho n>\mu / \rho n^{2}$ if and only if $\bar{r}<\alpha-\mu / n=r_{P},(21)$ then follows.

\footnotetext{
${ }^{13}$ Obviously, this requires that the banks' risk management systems be evaluated by the regulator, which is the subject of the so-called second pillar of the New Capital Accord.
} 
A prudent equilibrium with ceiling $\bar{r}$ will exist if no bank $j$ has an incentive to deviate from a situation in which all the banks offer the deposit rate $\min \left\{\bar{r}, r_{P}\right\}$ and invest in the prudent asset, that is if the following no gambling condition holds:

$$
\max _{r_{j} \leq \bar{r}}\left[\frac{1-\pi}{1+\rho}\left(\gamma-r_{j}\right) D\left(r_{j}, \min \left\{\bar{r}, r_{P}\right\}\right)+\frac{1-\pi}{1+\rho} V_{P}(\bar{r})\right] \leq V_{P}(\bar{r}) .
$$

As before, the left hand side of this expression is the present value of the deviation to the gambling strategy at any date $t$, which incorporates the constraint that the deposit rate offered by bank $j$ cannot exceed the ceiling, the while the right hand side is the value of the bank in the prudent equilibrium.

The following result examines under what conditions deposit rate ceilings can ensure the existence of a prudent equilibrium when $\mu / n<m_{P}$.

Proposition 3 If $\mu / n<m_{P}$, there are two critical values

$$
\gamma_{N B}=\alpha+\left(h^{2}-1\right) \frac{\mu}{n} \quad \text { and } \quad \gamma_{B}=\alpha h^{2},
$$

where $h$ is given by (13), such that if $\gamma>\gamma_{N B}$ there does not exist a deposit rate ceiling $\bar{r} \geq r_{P}$ for which a prudent equilibrium exists, and if $\gamma>\gamma_{B}$ there does not exist a deposit rate ceiling $\bar{r} \geq 0$ for which a prudent equilibrium exists.

In order to discuss this result it is convenient to use the definition of the intercept $m_{P}=m_{P}(0)$ to rewrite the condition $\mu / n<m_{P}$ in the following manner:

$$
\gamma>\gamma_{P}=\alpha+2(h-1) \frac{\mu}{n} .
$$

It is immediate to check that the critical values $\gamma_{P}, \gamma_{N B}$, and $\gamma_{B}$ defined in (23) and (24) are such that $\gamma_{P}<\gamma_{N B}$ if and only if $2(h-1)<\left(h^{2}-1\right)$, that is if and only if $(h-1)^{2}>0$, and $\gamma_{N B}<\gamma_{B}$ if and only if $\alpha>\mu / n$. Hence we have

$$
\gamma_{P}<\gamma_{N B}<\gamma_{B}
$$

Given that $\partial h / \partial \rho<0$, these critical values are decreasing functions of the cost of capital $\rho$, so we have the following four regions in the $\gamma-\rho$ space: region $\mathrm{P}$ below $\gamma_{P}(\rho)$ in which a prudent equilibrium exists, region $\mathrm{P}_{N B}$ between $\gamma_{P}(\rho)$ and $\gamma_{N B}(\rho)$ in which a prudent equilibrium can be sustained by a nonbinding deposit rate ceiling, region 
$\mathrm{P}_{N B}$ between $\gamma_{N B}(\rho)$ and $\gamma_{B}(\rho)$ in which a prudent equilibrium can be sustained by a binding deposit rate ceiling, and region NP above $\gamma_{B}(\rho)$ in which there is no prudent equilibrium for any value of the ceiling $\bar{r} \geq 0$. These regions are depicted in Figure 3 , in which the origin corresponds to the point $\gamma=\rho=\alpha .^{14}$

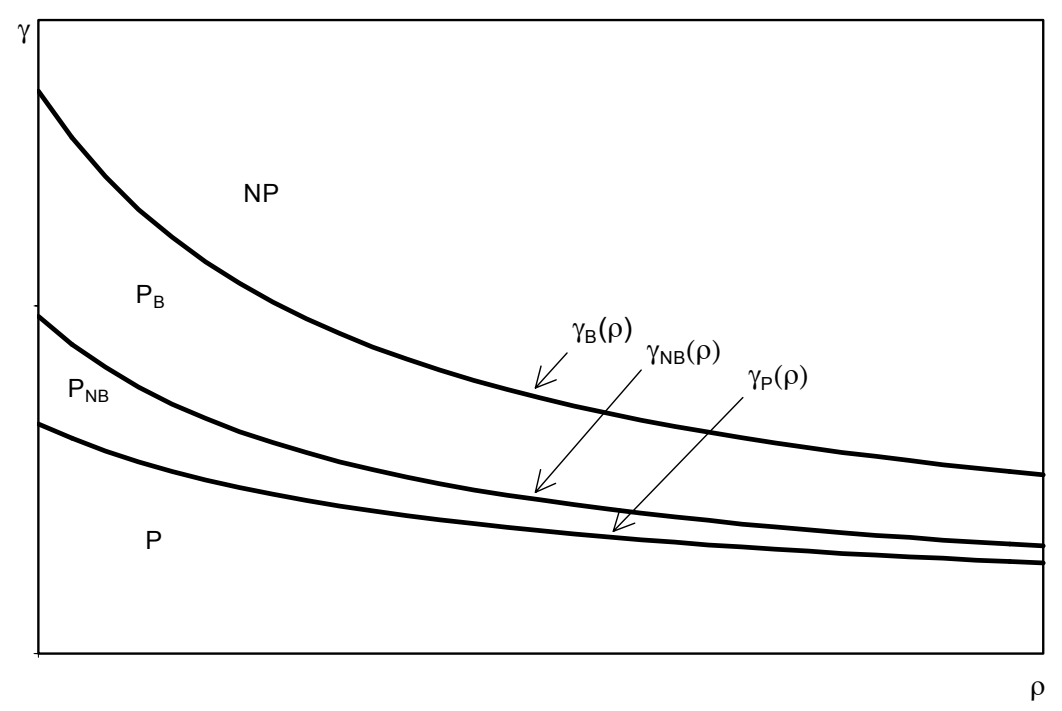

Figure 3: Characterization of equilibrium with deposit rate ceilings

Hence we conclude that deposit rate ceilings can ensure the existence of prudent equilibria that otherwise would not exist, unless either the success return of the gambling asset $\gamma$ or the cost of capital $\rho$ are sufficiently large (specifically, $\gamma>\gamma_{B}(\rho)$ ). The intuition for these results is the following. First, if investment in the gambling asset becomes very attractive for the banks' shareholders, they will not refrain from investing in this asset even when the future rents associated with investment in the prudent asset reach the upper bound $\alpha / n$ that obtains for $\bar{r}=0$. Second, if the cost of capital is very large, the present value of the higher future rents associated with the prudent investment will be small, so the banks will have an incentive to gamble.

\footnotetext{
${ }^{14}$ Notice that $\alpha \geq(1-\pi) \gamma-\pi$ if and only if $\gamma \leq(\alpha+\pi) /(1-\pi)=\gamma_{B}(\alpha)$, so values of $\gamma$ greater than $\gamma_{B}(\alpha)$ violate assumption (1).
} 


\section{Conclusion}

This paper has reexamined the role of capital requirements and deposit rate ceilings as a regulatory tools to reduce risk-taking incentives in situations of increased competition in banking. Contrary to the claim in Hellmann, Murdock, and Stiglitz (2000), we show that the former are always effective, while the latter may not always work.

The reason for our different results lies in the fact that in our model of imperfect competition in the deposit market, the costs of an increase in the capital requirement are fully translated to the depositors. Since the equilibrium intermediation margins remain constant, the banks' franchise values do not change, and so the only effect of a higher requirement is to increase the capital loss to the bank shareholders in case of default. Hence we conclude that capital requirements ameliorate the risk-shifting moral hazard problem, especially when they can be designed to penalize investment in riskier assets. Deposit rate ceilings, on the other hand, may provide higher rents and increase the banks' franchise values (if they are binding) and may reduce the profits from a deviation to riskier investments (if they are not), but this may not suffice to prevent the banks from taking excessive risk. 


\section{Appendix}

Proof of Proposition 1 Differentiating the left hand side of the no gambling condition (10) with respect to $r_{j}$, and using the demand function (3), gives the following first order condition:

$$
-\frac{k}{\mu}+\frac{1-\pi}{1+\rho}\left[\frac{\gamma-r_{j}+k(1+\gamma)}{\mu}-\left(\frac{1}{n}+\frac{r_{j}-r_{P}(k)}{\mu}\right)\right]=0 .
$$

Solving for $r_{j}$ in this expression and using the definition (8) of $r_{G}(k)$ we conclude that the deviating bank $j$ will offer the deposit rate

$$
r_{j}=\frac{r_{G}(k)+r_{P}(k)}{2} .
$$

Substituting this result back into (10) and rearranging then gives

$$
\frac{1-\pi}{1+\rho}\left(\frac{\left(r_{G}(k)-r_{P}(k)\right)^{2}}{4 \mu}+\frac{r_{G}(k)-r_{P}(k)}{n}+\frac{\mu}{n^{2}}\right)+\frac{1-\pi}{1+\rho} V_{P} \leq V_{P} .
$$

Substituting $V_{P}$ from (6) into this expression, and using the definition (13) of $h$ and the fact that by (5) and (8) we have $r_{G}(k)-r_{P}(k)=\gamma-\alpha-\delta k$, the condition for the existence of a prudent equilibrium simplifies to

$$
\frac{1}{4}(\gamma-\alpha-\delta k)^{2}+(\gamma-\alpha-\delta k) \frac{\mu}{n}-\left(h^{2}-1\right)\left(\frac{\mu}{n}\right)^{2} \leq 0 .
$$

Since $\mu / n>0$, it is immediate to check that for $\gamma-\alpha-\delta k \geq 0$ this inequality will be satisfied if

$$
\frac{\mu}{n} \geq \frac{\gamma-\alpha-\delta k}{2(h-1)}=m_{P}(k)
$$

Differentiating the left hand side of the no prudent condition (11) with respect to $r_{j}$, and using the demand function (3), gives the following first order condition:

$$
-\frac{k}{\mu}+\frac{1}{1+\rho}\left[\frac{\alpha-r_{j}+k(1+\alpha)}{\mu}-\left(\frac{1}{n}+\frac{r_{j}-r_{G}(k)}{\mu}\right)\right]=0 .
$$

Solving for $r_{j}$ in this expression and using the definition (5) of $r_{P}(k)$ we conclude that the deviating bank $j$ will offer the deposit rate

$$
r_{j}=\frac{r_{G}(k)+r_{P}(k)}{2} .
$$


Substituting this result back into (11) and rearranging then gives

$$
\frac{1}{1+\rho}\left(\frac{\left(r_{G}(k)-r_{P}(k)\right)^{2}}{4 \mu}-\frac{r_{G}(k)-r_{P}(k)}{n}+\frac{\mu}{n^{2}}\right)+\frac{1}{1+\rho} V_{G} \leq V_{G} .
$$

Substituting $V_{G}$ from (9) into this expression, and using the definition (13) of $h$ and the fact that $r_{G}(k)-r_{P}(k)=\gamma-\alpha-\delta k$, the condition for the existence of a gambling equilibrium simplifies to

$$
\frac{1}{4}(\gamma-\alpha-\delta k)^{2}-(\gamma-\alpha-\delta k) \frac{\mu}{n}+\left(1-\frac{1}{h^{2}}\right)\left(\frac{\mu}{n}\right)^{2} \leq 0 .
$$

It is immediate to check that this inequality will be satisfied if

$$
\frac{h(\gamma-\alpha-\delta k)}{2(h+1)} \leq \frac{\mu}{n} \leq \frac{h(\gamma-\alpha-\delta k)}{2(h-1)} .
$$

However for $\mu / n=(\gamma-\alpha-\delta k) / 2$ the demand for deposits of bank $j$ becomes

$$
D\left(\frac{r_{G}(k)+r_{P}(k)}{2}, r_{G}(k)\right)=\frac{1}{n}+\frac{r_{P}(k)-r_{G}(k)}{2 \mu}=\frac{1}{\mu}\left(\frac{\mu}{n}-\frac{\gamma-\alpha-\delta k}{2}\right)=0,
$$

so for smaller values of $\mu / n$ the deviation is never profitable. Hence we conclude that the condition for the existence of a gambling equilibrium is

$$
\frac{\mu}{n} \leq \frac{h(\gamma-\alpha-\delta k)}{2(h-1)}=h m_{P}(k)=m_{G}(k) .
$$

Finally, notice that $h>1$ if and only if $\rho+\pi>(1-\pi) \rho$, that is if and only if $\pi(1+\rho)>0$, and that by assumptions (2) and (1) we have

$$
\delta=\alpha-\gamma+\frac{\pi(1+\rho)}{1-\pi}>\alpha-\gamma+\frac{\pi(1+\alpha)}{1-\pi}=\frac{\alpha-[(1-\pi) \gamma-\pi]}{1-\pi} \geq 0 .
$$

Proof of Proposition 2 Differentiating the left hand side of the no gambling condition (17) with respect to $r_{j}$, and using the demand function (3), gives the following first order condition:

$$
-\frac{k}{\mu}+\frac{1-\pi}{1+\rho}\left[\frac{\gamma-r_{j}+k(1+\gamma)}{\mu}-\left(\frac{1}{n}+\frac{r_{j}-r_{P}}{\mu}\right)\right]=0 .
$$

Solving for $r_{j}$ in this expression and using the definition (8) of $r_{G}(k)$ we conclude that the deviating bank $j$ will offer the deposit rate

$$
r_{j}=\frac{r_{G}(k)+r_{P}}{2}
$$


Substituting this result back into (17) and rearranging then gives

$$
\frac{1-\pi}{1+\rho}\left(\frac{\left(r_{G}(k)-r_{P}\right)^{2}}{4 \mu}+\frac{r_{G}(k)-r_{P}}{n}+\frac{\mu}{n^{2}}\right)+\frac{1-\pi}{1+\rho} V_{P} \leq V_{P} .
$$

Substituting $V_{P}$ from (6) into this expression, and using the definition (13) of $h$ and the fact that by (8) and (16) we have $r_{G}(k)-r_{P}=\gamma-\alpha-\delta^{\prime} k$, the condition for the existence of a prudent equilibrium simplifies to

$$
\frac{1}{4}\left(\gamma-\alpha-\delta^{\prime} k\right)^{2}+\left(\gamma-\alpha-\delta^{\prime} k\right) \frac{\mu}{n}-\left(h^{2}-1\right)\left(\frac{\mu}{n}\right)^{2} \leq 0
$$

Since $\mu / n>0$, it is immediate to check that for $\gamma-\alpha-\delta^{\prime} k \geq 0$ this inequality will be satisfied if

$$
\frac{\mu}{n} \geq \frac{\gamma-\alpha-\delta^{\prime} k}{2(h-1)}=m_{P}^{\prime}(k)
$$

Differentiating the left hand side of the no prudent condition (18) with respect to $r_{j}$, and using the demand function (3), gives the following first order condition:

$$
\frac{\alpha-r_{j}}{\mu}-\left(\frac{1}{n}+\frac{r_{j}-r_{G}(k)}{\mu}\right)=0 .
$$

Solving for $r_{j}$ in this expression and using the definition (16) of $r_{P}$ we conclude that the deviating bank $j$ will offer the deposit rate

$$
r_{j}=\frac{r_{G}(k)+r_{P}}{2}
$$

Substituting this result back into (18) and rearranging then gives

$$
\frac{1}{1+\rho}\left(\frac{\left(r_{G}(k)-r_{P}\right)^{2}}{4 \mu}-\frac{r_{G}(k)-r_{P}}{n}+\frac{\mu}{n^{2}}\right)+\frac{1}{1+\rho} V_{G} \leq V_{G} .
$$

Substituting $V_{G}$ from (9) into this expression, and using the definition (13) of $h$ and the fact that $r_{G}(k)-r_{P}=\gamma-\alpha-\delta^{\prime} k$, the condition for the existence of a gambling equilibrium simplifies to

$$
\frac{1}{4}\left(\gamma-\alpha-\delta^{\prime} k\right)^{2}-\left(\gamma-\alpha-\delta^{\prime} k\right) \frac{\mu}{n}+\left(1-\frac{1}{h^{2}}\right)\left(\frac{\mu}{n}\right)^{2} \leq 0 .
$$

It is immediate to check that this inequality will be satisfied if

$$
\frac{h\left(\gamma-\alpha-\delta^{\prime} k\right)}{2(h+1)} \leq \frac{\mu}{n} \leq \frac{h\left(\gamma-\alpha-\delta^{\prime} k\right)}{2(h-1)}
$$


However for $\mu / n=\left(\gamma-\alpha-\delta^{\prime} k\right) / 2$ the demand for deposits of bank $j$ becomes

$$
D\left(\frac{r_{G}(k)+r_{P}}{2}, r_{G}\right)=\frac{1}{n}+\frac{r_{P}-r_{G}(k)}{2 \mu}=\frac{1}{\mu}\left(\frac{\mu}{n}-\frac{\gamma-\alpha-\delta^{\prime} k}{2}\right)=0,
$$

so for smaller values of $\mu / n$ the deviation is never profitable. Hence we conclude that the condition for the existence of a gambling equilibrium is

$$
\frac{\mu}{n} \leq \frac{h\left(\gamma-\alpha-\delta^{\prime} k\right)}{2(h-1)}=h m_{P}^{\prime}(k)=m_{G}^{\prime}(k) .
$$

Finally, by assumptions (2) and (1) we have

$$
\delta^{\prime}=\frac{1+\rho}{1-\pi}-(1+\gamma)>\frac{1+\alpha}{1-\pi}-(1+\gamma)=\frac{\alpha-[(1-\pi) \gamma-\pi]}{1-\pi} \geq 0
$$

Proof of Proposition 3 Suppose first that $\bar{r}=r_{P}=\alpha-\mu / n$. Differentiating the left hand side of the no gambling condition (22) with respect to $r_{j}$, and evaluating it at $r_{j}=\bar{r}$, gives

$$
\frac{1-\pi}{1+\rho}\left(\frac{\gamma-\bar{r}}{\mu}-\frac{1}{n}\right)=\frac{1-\pi}{1+\rho} \frac{\gamma-\alpha}{\mu}>0
$$

so we have a corner solution $r_{j}=\bar{r}$. Substituting this result back into (22), and using (21) then gives

$$
\frac{1-\pi}{1+\rho}\left(\frac{\gamma-\alpha+\mu / n}{n}+\frac{\mu}{\rho n^{2}}\right) \leq \frac{\mu}{\rho n^{2}}
$$

which using the definition of $h$ in (13) simplifies to

$$
\gamma \leq \alpha+\frac{\pi(1+\rho)}{(1-\pi) \rho} \frac{\mu}{n}=\left(h^{2}-1\right) \frac{\mu}{n}=\gamma_{N B}
$$

Hence if this condition is not satisfied, the deviation will be profitable, and a prudent equilibrium will not exist. Moreover, since the maximized value of the left hand side of (22) is increasing in $\bar{r}$ for $\bar{r}<\left(r_{G}+r_{P}\right) / 2$, it follows that if $\gamma>\gamma_{N B}$ a prudent equilibrium will not exist for any ceiling $\bar{r} \geq r_{P}$.

Suppose next that $\bar{r}<r_{P}$. Differentiating the left hand side of the no gambling condition (22) with respect to $r_{j}$, and evaluating it at $r_{j}=\bar{r}$, gives

$$
\frac{1-\pi}{1+\rho}\left(\frac{\gamma-\bar{r}}{\mu}-\frac{1}{n}\right)=\frac{1-\pi}{1+\rho} \frac{\gamma-\alpha}{\mu}>0
$$


so again we have a corner solution $r_{j}=\bar{r}$. Substituting this result back into (22), and using (21) then gives

$$
\frac{1-\pi}{1+\rho}\left(\frac{\gamma-\bar{r}}{n}+\frac{\alpha-\bar{r}}{\rho n}\right) \leq \frac{\alpha-\bar{r}}{\rho n}
$$

which using the definition of $h$ in (13) simplifies to

$$
\gamma \leq \frac{\alpha(\rho+\pi)}{(1-\pi) \rho}-\frac{\pi(1+\rho)}{\rho} \bar{r}=\alpha h^{2}-\frac{\pi(1+\rho)}{\rho} \bar{r}=\gamma_{B}-\frac{\pi(1+\rho)}{\rho} \bar{r} .
$$

Since the right hand side of this expression is decreasing in $\bar{r}$, this condition is most likely to hold for $\bar{r}=0$. Hence we conclude that if $\gamma>\gamma_{B}$ the deviation will be profitable, and a prudent equilibrium will not exist for any ceiling $\bar{r}<r_{P}$. 


\section{References}

[1] Basle Committee on Banking Supervision (2001): The New Basel Capital Accord.

[2] Besanko, D., and G. Kanatas (1996): "The Regulation of Bank Capital: Do Capital Standards Promote Bank Safety?," Journal of Financial Intermediation, 5, 160-183.

[3] Blanchard, O. (1985), "Debt, Deficits, and Finite Horizons," Journal of Political Economy, 93, 223-247.

[4] Chiappori, P.-A., D. Pérez-Castrillo, and T. Verdier (1995): "Spacial Competition in the Banking System: Localization, Cross Subsidies, and the Regulation of Deposit Rates," European Economic Review, 39, 889-918.

[5] Fudenberg, D., and J. Tirole (1991): Game Theory, MIT Press.

[6] Furlong, F. T., and M. C. Keeley (1989): "Capital Regulation and Bank RiskTaking: A Note," Journal of Banking and Finance, 13, 883-891.

[7] Genotte, G., and D. Pyle (1991): "Capital Controls and Bank Risk-Taking," Journal of Banking and Finance, 15, 805-824.

[8] Hellmann, T. F., K. C. Murdock, and J. E. Stiglitz (2000): "Liberalization, Moral Hazard in Banking, and Prudential Regulation: Are Capital Requirements Enough?" American Economic Review, 90, 147-165.

[9] Keeley, M. C. (1990): "Deposit Insurance, Risk, and Market Power in Banking," American Economic Review, 80, 1183-1200.

[10] Matutes, C., and X. Vives (1996): "Competition for Deposits, Fragility, and Insurance," Journal of Financial Intermediation, 5, 184-216.

[11] Matutes, C., and X. Vives (2000): "Imperfect Competition, Risk-Taking, and Regulation in Banking," European Economic Review, 44, 1-34.

[12] Perotti, E., and J. Suarez (2001): "Last Bank Standing: What Do I Gain if you Fail?" CEPR Discussion Paper No. 2933. 
[13] Repullo, R. (2000): "Who Should Act as Lender of Last Resort? An Incomplete Contracts Model," Journal of Money, Credit and Banking, 32, 580-605.

[14] Repullo, R. (2002): “Are Capital Requirements Enough? A Comment," mimeo.

[15] Rochet, J.-C. (1992): "Capital Requirements and the Behaviour of Commercial Banks," European Economic Review, 36, 1137-1170.

[16] Salop, S. (1979): "Monopolistic Competition with Outside Goods," Bell Journal of Economics, 10, 141-156.

[17] Suarez, J. (1994): "Closure Rules, Market Power and Risk-Taking in a Dynamic Model of Bank Behaviour," LSE Financial Markets Group Discussion Paper No. 196. 